\title{
Au-delà des yeux glacés
}

"...Après avoir eu trente ans, j'ai découvert que les cours les plus brûlés, les plus blessés, se cachent très souvent au-delà des yeux les plus glacés ... »

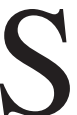
on regard était très froid, voire glacé. Son visage, gris, dur, impénétrable. Ses mains croisées sur sa poitrine.

J'avais l'impression que je regardais une photo ancienne en noir et blanc, peut-être même en noir seulement. Je sais pas comment dire ça, mais elle me semblait être ... un être "peu vivant».

Les traits très peu expressifs, la voix à peine audible, très monotone, je la trouvais très peu intéressante et motivante, point aimable.

C'était sa première visite à ma clinique.

"Bonjour madame. Comment je peux vous aider?»

Et le téléphone sonna. C'était l'infirmière qui m'appelait de dehors.

"Docteur, le directeur de section où travaille $M^{\text {me }}$ N.M., la patiente que vous voyez maintenant, vient de nous appeler pour vous dire qu'il croit qu'elle vous visite pour obtenir un rapport d'absentéisme. Il a dit qu'elle visite les médecins chaque une ou deux semaines pour demander des rapports d'absentéisme, depuis quelques mois. »

"C'est pourquoi elle me paraît si peu plaisante et aimable, " songeai-je. "Peut-être est-elle en train d'inventer une histoire. C'est pourquoi je n'ai pas aimé son visage. »

"Je prendrai ça en considération », répondis-je à l'infirmière. "Alors, madame, je vous écoute. »

"Docteur, j'ai très mal aux genoux depuis longtemps et ça devient plus sévère, » murmura-t-elle sur un ton très sec. Je la regardai droit dans les yeux, son regard était figé, inerte. Je me souvins de ce que l'infirmière m'avait dit. Il me parut que la patiente ne sentait point la douleur dont elle parlait.

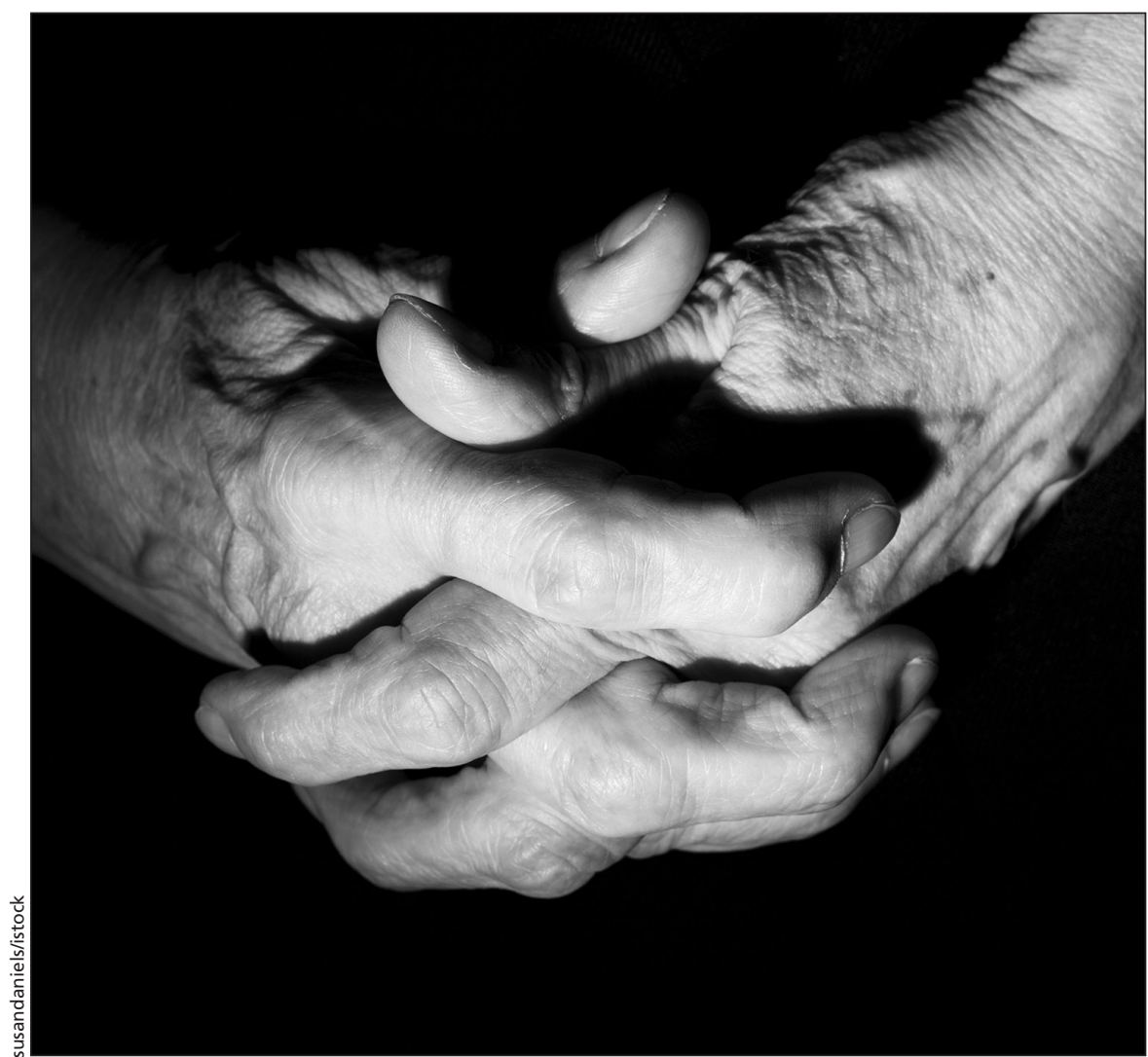

"Alors votre douleur est très sévère? »

«Oui », répondit-elle, très en bref et sans aucune expression.

"J'aimerais vous examiner s'il vous plait.»

Je manipulai ses genoux sans trop me concentrer sur ce que je faisais car son visage ne m'en disait pas long, en fait, il ne me disait rien du tout.

Elle commençait à m'irriter.

"Les médicaments soulagent à peine ma douleur, docteur », murmurat-elle sans me regarder. "Allez-vous me donner un rapport de maladie pour me reposer un peu? »

Maintenant j'étais sûre que son directeur avait raison.

"Madame, je ne vois aucune raison pour que vous vous reposiez. Je vais vous prescrire un médicament antal- gique qui devrait faire l'affaire ... euh ... et puis, vous savez, votre directeur m'a appelée pour me dire que vous vous absentez beaucoup depuis quelque temps. »

Je venais de finir ma phrase avec beaucoup de confiance et pas peu d'autorité quand la scène morte et ennuyante qui prenait place dans ma clinique se changea soudainement en scène dramatique : le visage gris s'engorgea soudainement et devint très rouge, les yeux glacés tout d'un coup devinrent en flammes, les mains croisées devinrent fort serrées en poings, la voix monotone devint très élevée, très vibrante.

"Docteur, est-ce que vous appelez aucune raison avoir à élever toute seule un enfant âgé d'un an, est-ce que vous appelez aucune raison avoir à tra- 
vailler comme servante dans les maisons des voisins chaque jour après mon travail du matin pour pouvoir survivre? Est-ce que vous appelez aucune raison avoir vraiment très mal aux genoux depuis bien longtemps, mais surtout avoir trop mal au cour, et depuis beaucoup plus longtemps.

Ne croyez-vous pas que la douleur dans le cour ça mérite aussi, comme toutes les douleurs, quelque repos? Pourquoi, docteur... pourquoi pouvezvous croire mon directeur mais ne point croire mon cour?»

Je ne compris aucun mot de ce qu'elle venait de dire. Mon attrait pour le dramatisme me dit pourtant que c'était une scène « vraie », point «fabriquée » ou « jouée ».

J'étais toujours très confiante et autoritaire pourtant. J'avais dans la tête ce que le directeur et l'infirmière avaient dit. Après tout, un médecin ne doit jamais se laisser manipuler par un patient. C'est comme ça qu'on nous apprend. Et il doit toujours être plus intelligent.

"Excusez-moi, madame, je n'ai pas compris ce que vous venez de dire. »

Et c'est alors que la scène se dramatisa tout à fait. Ses larmes commencèrent à couler en cascades, ses sanglots résonnaient dans la clinique, elle grelottait de la tête aux pieds.

Je commençai à lâcher prise sur mon « intelligence », sur ma confiance, sur mon autorité, sur sa «soi-disant» manipulation.

«Docteur, vous avez dit que vous ne voyez aucune raison pour me reposer. Comment et où avez-vous vu ça? Dans mon visage ou dans mes genoux? Docteur, avez-vous vu mon jeune fils de trente ans qui est mort il y a cinq mois?
Avez-vous vu son enfant d'un an, mon petit-fils, qu'il a abandonné derrière lui? Avez-vous vu sa jeune femme qui est retournée dans son pays d'origine après la mort de son mari? Avez-vous vu comment elle m'a laissé l'enfant? Sans père, ni mère, rien qu'une grandmère de soixante ans pour l'élever. Avez-vous vu la petite chambre au cinquième étage où je vis, dans un immeuble sans ascenseur? Avez-vous $v u$ mon salaire très médiocre et mes poches vides? Avez-vous vu les heures que je travaille chaque jour comme servante chez les voisins après mon travail du matin pour nourrir l'enfant? Avez-vous vu les soirs que je veille à le calmer? Mais avez-vous vu ma douleur? Avez-vous senti la douleur que je sens dans mes genoux? Avez-vous vu la grande douleur que je porte dans mon cour? Pouvez-vous la voir? Pouvezvous la sentir? Comment avez-vous vu que je ne mérite pas de me reposer? Vous n'avez vu que mon visage, que mes genoux, mais rien d'autre. "

Mes joues étaient très chaudes, mes larmes les brûlaient. Mon " intelligence », ma confiance et mon autorité n'existaient plus. J'avais quitté mon monde et pénétré le sien. Je voyais l'histoire cachée au-delà des quatre murs de ma clinique, au-delà de mon anamnèse sacrée, au-delà de ses yeux glacés.

Je ne lui dis aucun mot. Je me trouvai soudainement à genoux, devant elle, serrant ses deux poings déjà très fort serrés. Je ne trouvai pas l'expression, mais je crois que j'avais envie de lui dire pardon. Eh bien oui, elle était donc vraiment «un être peu vivant », mais pas telle que je l'avais vue avant.
Je continuai à vivre et à ruminer la scène dramatique pour une bonne semaine, à écrire un tas de réflexions sur chaque papier qui me tombait sous la main pour un bon mois, à analyser et disséquer chaque petit mot que murmure chacun de mes patients et jusqu'à présent, je crains toujours de faillir à voir au-delà des yeux d'un patient, surtout à travers des yeux glacés. Je me demande jusqu'à maintenant quand je vois un patient si j'ai réussi à sonder son histoire cachée, celle qui a peut-être créé l'histoire qu'il me raconte.

... Après avoir eu trente ans, j'ai appris à examiner la douleur des cœurs comme j'ai si bien appris à examiner celle des genoux. J'ai appris à croire les cœurs avant les directeurs. Après avoir eu trente ans je suis arrivée à aimer les yeux glacés, ils ne me repoussent plus ... ils m'attirent plutôt. Après avoir eu trente ans, j'ai appris à écouter le ton morne dans une voix monotone et à voir les regards ternes dans des yeux inertes. Après avoir eu trente ans, ça me flatte un peu moins d'écouter des compliments sur mes grands yeux qui parlent sans cesse et qui me trahissent rondement. Après avoir eu trente ans, j'ai découvert que les cœurs les plus brûlés, les plus blessés, se cachent très souvent au-delà des yeux les plus glacés.

\section{Fadila Naji MD}

Université Américaine de Beyrouth, Beyrouth, Liban

Tous les personnages apparaissant dans cet ouvrage sont fictifs. Toute ressemblance avec des personnes existantes ou ayant existé ne serait que pure coïncidence.

CMAJ 2015. DOI:10.1503/cmaj.141615 